University of Massachusetts Amherst

ScholarWorks@UMass Amherst

Masters Theses 1911 - February 2014

1981

\title{
The discriminative stimulus properties of fenfluramine: evidence for serotonergic involvement/
}

John F. Mcelroy

University of Massachusetts Amherst

Follow this and additional works at: https://scholarworks.umass.edu/theses

Mcelroy, John F., "The discriminative stimulus properties of fenfluramine: evidence for serotonergic involvement/" (1981). Masters Theses 1911 - February 2014. 1782.

https://doi.org/10.7275/j0fb-fd83

This thesis is brought to you for free and open access by ScholarWorks@UMass Amherst. It has been accepted for inclusion in Masters Theses 1911 - February 2014 by an authorized administrator of ScholarWorks@UMass Amherst. For more information, please contact scholarworks@library.umass.edu. 
UMASS/AMHERST

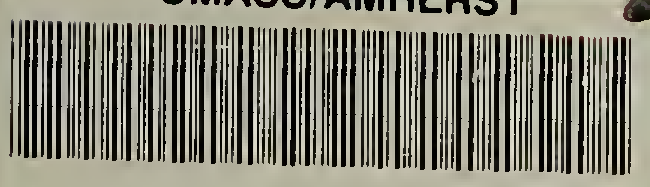

31.2066013566606 
THE DISCRIMINATIVE STIMULUS PROPERTIES OF FENFLURAMINE:

EVIDENCE FOR SEROTONERGIC INVOLVEMENT

A Thesis Presented

By

JOHN FRANCIS MCELROY

Submitted to the Graduate School of the University of Massachusetts in partial fulfillment

of the requirements for the degree of

MASTER OF SCIENCES

May

1981

Department of Psychology 
THE DISCRIMINATIVE SIIMULUS PROPERTIES OF FENFLURAMINE: EVIDENCE FOR SEROTONERGIC INVOLVEMENT

\section{A Thesis Presented}

By.

JOHN FRANCIS MCELROY

Approved as to style and content by:
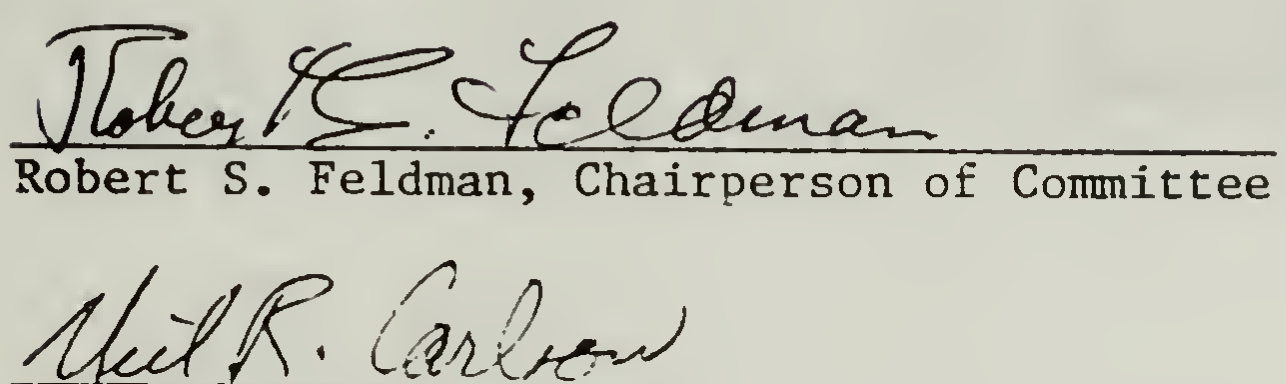

Neil R. Carlson, Member

$\frac{\text { Whuchingenere }}{\text { John w. Donahoe, Nember }}$

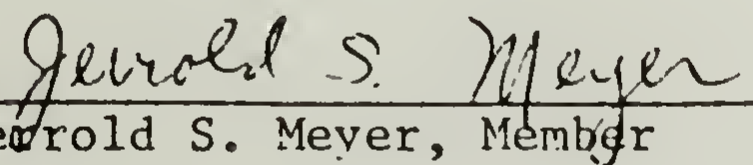

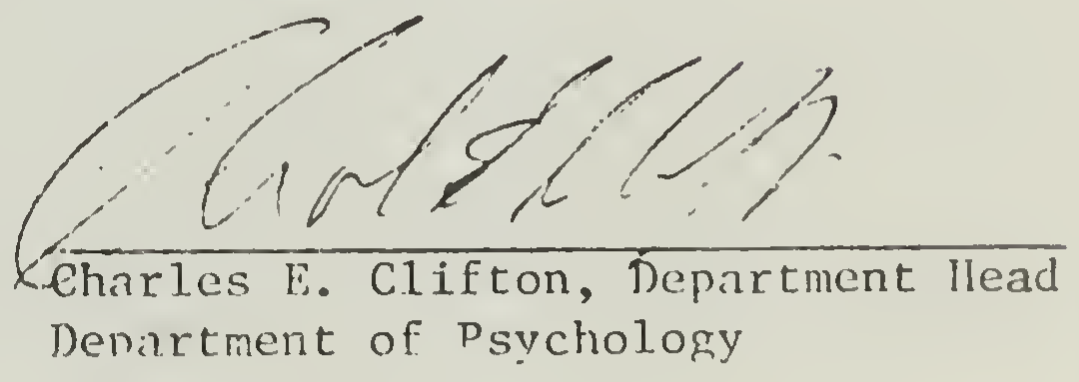




\section{ACKNOWLEDGEMENTS}

I would like to especially thank my friend and advisor, Dr. Robert S. Feldman, first for having been instrumental in the conceptualization of this study; and secondly for delicately catering to my stubborn independence, while at the same time providing direction and support in my times of need. I would also like to thank the members of my committee for their helpful comments and suggestions in the design of this investigation.

My warmest appreciation goes to Nancy Feldman for rendering Figures 2 through 9, and to Chris Decoteau for the typing of this thesis. Special thanks are also due to Mike Czupryna, Ted Tyler, and Brad Webber for their excellent technical assistance. 
ACKNOWLEDGEMENTS • . . . . . . . . . . . . . . .

LIST OF TABLES

LIST OF FIGURES

INTRODUCTION

METHOD AND PROCEDURE

Subjects

Apparatus

Drugs

Preliminary training ..........

Discrimination training. . . . . . . . . . . . .

Test sessions . . . . . . . . . . . . . . .

Data analysis . . . . . . . . . . . . . . .

RESULTS AND DISCUSSION . . . . . . . . . . . . . . 9

Experiment 1, time course of drug action . . . . . 10

Experiment 2, the dose response curve . . . . . . 12

Experiment 3, isomeric specificity of the

fenfluramine cue . . . . . . . . . . . . .

Experiment 4, generalization of the fenfluramine

cue ....................

Experiment 5, antagonism of the fenfluramine cue . .

Experiment 6, fluoxetine-fenfluramine interactions

Experiment 7, Is satiety the fenfluramine cue? . . . 26

GENERAL DISCUSSION • • . . . . . . . . . . . . 30

REFERENCES •. • . . . . . . . . . . . . . 33 


\section{LIST OF TABLES}

1. Discriminative Properties of Fenfluramine and Related Compounds . . . . . . . . . . . . . 


\section{LIST OF FIGURES}

1. Structural formulas of amphetamine and fenfluramine

2. Percent responding on the fenfluramine lever as a function of time . . . . . . . . . . . . . . 11

3. Percent responding on the fenfluramine lever as a function of dose .. . . . . . . . . . . . 13

4. Percent responding on the fenfluramine lever as a function of dose of either $(+)-$, or $(-)-$, or $( \pm)$-fenfluramine ................. 16

5. Percent responding on the fenfluramine lever as a function of dose of either PCA or PFA . . . . . . 19

6. Percent responding on the fenfluramine lever as a function of dose of methysergide . . . . . . . 21

7. Percent responding on the fenfluramine lever as a function of dose of cinanserin . . . . . . . 22

8. Percent responding on the fenfluramine lever as a function of dose of fluoxetine. . . . . . . . . 24

9. Rate of responding and latency of first response as a function of length of food deprivation . . . . 28 


\section{INTRODUCTION}

The first drug to be found useful in suppressing appetite was amphetamine (Lesser and Meyerson, 1938). Amphetamine has potent central stimulant, cardiovascular, hyperthermic and anorectic properties, to all of which tolerance develops upon repeated use. The need for a more selective anorectic drug without the dangers of abuse and toxicity prompted numerous studies into the anorectic activity of a number of related compounds, all based upon the phenethylamine molecule. This led to the development of fenfluramine 1-(3-trifluoromethylpheny1)-2-ethylaminopropane (Alphin et al., 1964). Fenfluramine provided the appetite suppression characteristic of amphetamine without producing the central stimulation.

The structural formulas of amphetamine and fenfluramine are illustrated in Figure 1. It can be seen that the basic difference between these molecules is the addition of an ethyl group on the nitrogen atom and the substitution of a trifluoromethyl group on the phenyl ring.<smiles>CC(N)Cc1ccccc1</smiles>

AMPHETAMINE<smiles>CCNC(C)Cc1cccc(C(F)(F)F)c1</smiles>

FENFLURAMINE

Fig. 1. Structural formulas of amphetamine and fenfluramine. 
Several approaches have been used to establish the pharmacological identities of amphetamine and fenfluramine. One such approach has been the use of drug discrimination paradigms. Drug discrimination learning requires the drug to produce a perceivable change in some aspect of the organism's internal environment. By producing this interoceptive cue, the drug versus saline injections may then be applied as distinct discriminative stimuli, thus making it possible to train animals to perform one type of behavior for reinforcement following a drug injection and to perform a different, but topographically similar behavior following injection of saline.

In the majority of drug discrimination studies, the animal is required to either make opposite turns in a T-maze (Overton, 1978) or opposite choices in a two lever test chamber (Colpaert et al., 1976). Differential, but equivalent responses have also been trained in other test procedures, such as the Lashley jumping stand (Brown et al., 1968) and choices between side compartments of a 3-chambered apparatus (Schechter and Roescrans, 1973). The incentive for the correct response in these studies has either been food reward or escape from shock. When acquisition of such response differentiation is reliably shown, the drug is said to produce a discriminative stimulus.

Amphetamine has been extensively investigated in drug discrimination procedures. In brief, the results of testing a number of neurochemical agents for their ability to antagonize the amphetamine cue suggests no clear role of acetylcholine, norepinephrine or serotonin (Ho and Huang, 1975). The amphetamine cue was successfully 
antagonized by pimozide (Ho and Huang, 1975) and by haloperidol (Schechter and Cook, 1975), two dopamine receptor blockers. It was also shown that alpha-methyl-para-tyrosine, the catecholamine synthesis inhibitor (Kuhn et al., 1974; Rosecrans et al., 1973), but not disulfiram, the dopamine-beta-hydroxylase inhibitor (Schechter and Cook, 1975) was capable of antogonizing amphetamine's discriminative property. These results suggest involvement of the dopaminergic system in the discriminative stimulus property of amphetamine.

Despite reports of some amphetamine-like effects of fenfluramine (Everitt and Hackett, 1972; Clineschmidt et al., 1975; Taylor et al., 1973), evidence indicates that the interoceptive cues produced by fenfluramine are very different from those produced by amphetamine. Schechter and Rosecrans (1973) reported that in rats trained to discriminate $3 \mathrm{mg} / \mathrm{kg}$ amphetamine from saline, $4-8 \mathrm{mg} / \mathrm{kg}$ fenfluramine failed to generalize to the amphetamine cue. Similarly, it was found that rats trained to discriminate $3 \mathrm{mg} / \mathrm{kg}$ fenfluramine from saline failed to generalize to amphetamine at doses between 0.25 and $1 \mathrm{mg} / \mathrm{kg}$ (Goudie, 1977). These results suggest that different pharmacological mechanisms underlie the interoceptive cues produced by amphetamine and fenfluramine.

Since fenfluramine has been shown to exert a selective action on brain 5-hydroxytryptamine (5-HT, serotonin) concentrations (Opitz, 1967; Costa et al., 1971; Duhault and Boulanger, 1977; Clineschmidt et al., 1978), presumably by stimulating the release of 5-HT and 
blocking its reuptake at the neuronal synapse (Fuxe, 1975), it has been suggested that many of the behavioral changes induced by fenfluramine depend upon alterations in the 5-HT system. For example, it has been shown that 5-hydroxytryptophan (5-HTP), the precursor of 5-HT, mimics the anorectic (Blundell and Leshem, 1975) and hypothermic (Jespersen and Scheel-Kruger, 1970) effects of fenfluramine. It has also been reported that 5-HT receptor blocking drugs such as methergoline (Funderburk et a1., 1971; Jespersen and Scheel-Kruger, 1973) or cyproheptadine (Kruk, 1973) or methysergide (Jespersen and Scheel-Kruger, 1970; Blundel1 et al., 1973) antagonize the anorectic effects of fenfluramine. Moreover, electrolytic lesions of the midbrain raphe nuclei, an important site of origin of 5-HT neurons in the brain (Dahlstrom and Fuxe, 1964), abolished the anorexia produced by fenfluramine (Samanin et al., 1972).

In the light of the present pharmacological, biochemical and behavioral knowledge of fenfluramine, it seemed reasonable to suspect that the 5-HT system might be involved in the discriminative property of fenfluramine. More specifically, the action underlying the discriminative cue might consist of an indirect activation of the 5-HT system, because promotion of 5-HT release and the inhibition of its reuptake are known to increase synaptic concentrations of the transmitter substance.

The studies that are reported here are behavioral pharmacological investigations aimed at providing further information about the pharmacological identity of fenfluramine. The first phase of our research 
involved identification of the stimulus parameters produced by the administration of fenfluramine. Once this was established, I sought to explore the involvement of 5-HT in the discriminative stimulus property of fenfluramine. This involved a series of generalization and antagonism studies with serotonergic agents whose neuronal mechanisms of action are understood.

\section{METHOD AND PROCEDURE}

Subjects.

The subjects used in this experiment were 24 Holtzmann male albino rats obtained from the Holtzmann Co., Madison, Wisconsin. Each rat, weighing between 250-350 $\mathrm{g}$ at the start of the experiment, was housed in a cage measuring $24 \times 18 \times 19 \mathrm{~cm}$ in a temperature-controlled room with an alternating 12 hour 1ight/12 hour dark cycle. Water was freely available to all rats.

\section{Apparatus.}

The behavioral apparatus consisted of two standard Skinner boxes housed in light-proof, sound attenuated and fan ventilated chambers. Each Skinner box was equipped with two levers, one of which was placed on the right and the other on the left of a centrally placed dipper which delivered $0.1 \mathrm{cc}$ of a liquid food reinforcement for three seconds. The food was a 50/50 mixture of condensed milk and water, added to an equal volume of liquid Similac. Standard electromechanical programming and cumulative counters were used to control and record behavior. 


\section{Drugs.}

Fenfluramine hydrochloride (Robbins), fluoxetine hydrochloride and p-fluoroamphetamine hydrochloride (Eli Lilly), methysergide maleate (Sandoz) and cinanserin hydrochloride (Squibb) were generously donated. 5-hydroxytryptophan (Sigma) and p-chloroamphetamine hydrochloride (Regis) were purchased. All drugs were dissolved in $0.9 \%$ saline and were administered intraperitoneally (i.p.) in a volume of $2 \mathrm{cc} / \mathrm{kg}$ body weight.

\section{Preliminary training.}

Twelve rats were randomly assigned to each box. Discrimination training was done according to standard shaping procedures. Once lever pressing was well established, the animals (18 hours food deprived were trained to alternate between bars (only one bar was reinforced for 5 minutes, then the other, for a total of 30 minutes). When the animals began to alternate promptly following cessation of reinforcement, the reinforcement schedule was gradually increased to FR 10 .

\section{Discrimination training.}

Next, the animals were trained to discriminate between $3 \mathrm{mg} / \mathrm{kg}$ fenfluramine and physiological saline. Six out of the 12 rats assigned to each box, randomly selected, were assigned the left lever as "drug-correct" and the right lever as "saline-correct", while the order was reversed for the remaining 6 animals. All training and testing was done at the same time of the day, one hour 
before the daily feeding, for at least five consecutive days each week. Throughout the study, the feeding schedule (15-20 grams of standard Purina laboratory chow) maintained individual animals at $80 \pm 5 \%$ of normal body weight.

At the beginning of each session, each animal was injected with fenfluramine or saline 60 minutes prior to training. During testing, the following measures were recorded: the number of incorrect responses before the first reinforcement (errors), and the total number of responses at each lever. Discrimination sessions were 10 minutes in duration, at the end of which the animal was returned to its home cage. After 8 sessions of alternating saline and drug injections, the operant lever was varied according to the following two pseudorandom sequences:

$$
\begin{aligned}
& \text { fenfluramine-saline-saline-fenfluramine-fenfluramine } \\
& \text { and } \\
& \text { saline-fenfluramine-fenfluramine-saline-saline }
\end{aligned}
$$

Discrimination sessions were continued until all animals reached the criterion of no more than 3 incorrect responses before the first reinforcement on each of 9 out of 10 consecutive days.

\section{Test sessions.}

Once drug discrimination was well established, a series of generalization and antagonism studies were conducted. On test days, the reinforcement delivery system was disconnected (extinction), and the following measures were recorded: the lever on which the rat first 
made 10 responses (the selected lever), and the number of responses on the other lever before the 10th response was executed. As soon as the rat responded 10 times to either lever, or after 10 minutes had expired, testing was terminated and the rat was immediately removed from the experimental chamber.

Between test days, the animals were required to discriminate $3 \mathrm{mg} / \mathrm{kg}$ fenfluramine from saline on 4 consecutive days, each day with 3 or fewer errors. These retraining sessions, 10 minutes in duration, were in the order of saline-fenfluramine-fenfluraminesaline. If any animal failed to reach criterion, testing with that animal was postponed and discrimination training continued until that subject reached criterion.

Data analysis.

During novel drug testing, there is really no correct or incorrect lever, and the experimenter cannot know in advance how the animal will respond. For this reason, I immediately removed the rat from the experimental chamber as soon as it responded 10 times to either lever. At that time, the number of responses on either lever was recorded and the percent fenfluramine-correct lever selection for each animal was computed.

This procedure takes into account the "certainty" with which an animal selects a lever. Animals trained on a fixed-ratio schedule have to emit a certain number of responses before reinforcement can follow. Well trained animals make the necessary 10 presses on the correct lever with very few presses on the incorrect lever. There is 
an obvious difference between two animals, one of which presses the drug-correct lever with no errors and the other which emits the required number of responses interspersed with, say, 8 presses at the incorrect lever. The lever selection measure accounts for such a difference.

Unless otherwise indicated, each data point represents the mean ( \pm 1 SEM) percent fenfluramine-correct responding for 10 subjects, randomly selected from the available pool of animals, with the constraint that the rats were evenly distributed in terms of lever assignment.

\section{RESULTS AND DISCUSSION}

Acquisition and maintenance of saline-fenfluramine discrimination.

All subjects were run for at least 260, but not more than 315 operant sessions, except for one subject which was found dead in its cage on the day of its 38 th operant session.

The number of training sessions required for subjects to reach discrimination criterion ranged from 14 to 55 (including the 10 criterion sessions), with a median value of 22 .

Following the initial training period, discrimination sessions were conducted at least 4 times per week on further standard sessions and all animals reliably selected the appropriate lever after saline or fenfluramine treatment. Incorrect lever selections occurred rarely and each individual rat reached a highly significant level (one-tailed; $\mathrm{p}<0.001$; binomial test) of correct level selection. The median percent-correct lever selection value was $100 \%$ for each 
animal under either drug or saline treatment.

Averaged over the first 3 post-criterion saline treatments, the mean $\pm 1 \mathrm{SEM}$ response output ranged from $390 \pm 17.3$ to $1037 \pm 88.3$, with a median value of 648 responses per 10 minute training session. For fenfluramine treatments, this value ranged from $170 \pm 28.8$ to $977 \pm 25.2$, with a median value of 501 responses per 10 minute training session. The individual response lever over these 3 fenfluramine treatments (expressed as a percentage of the corresponding saline value) varied from 42.6 to $121 \%$, with a median value of $82.7 \%$ and a mean value of $78.2 \pm 5.6 \%$. This response decrease produced by $3 \mathrm{mg} / \mathrm{kg}$ fenfluramine was statistically significant (onetailed; $\mathrm{p}<0.005$; Wilcoxon-test).

\section{Experiment 1, the time course of drug action}

Initially, I hypothesized that establishment of the optimum stimulus parameters would contribute to the sensitivity in the investigation of drug interactions in the discrimination procedure. In particular, in studies involving drug antagonists, it is crucial to find the point at which the drug cue is most easily manipulated. For that reason, we next investigated the temporal parameters of the fenfluramine cue. This involved administering a $3 \mathrm{mg} / \mathrm{kg}$ dose of fenfluramine at various times prior to testing.

It can be seen in Fig. 2 that the fenfluramine cue shows a relatively fast onset, with greater than $60 \%$ fenfluramine-correct responding 10 minutes after injection. It can also be seen that the 


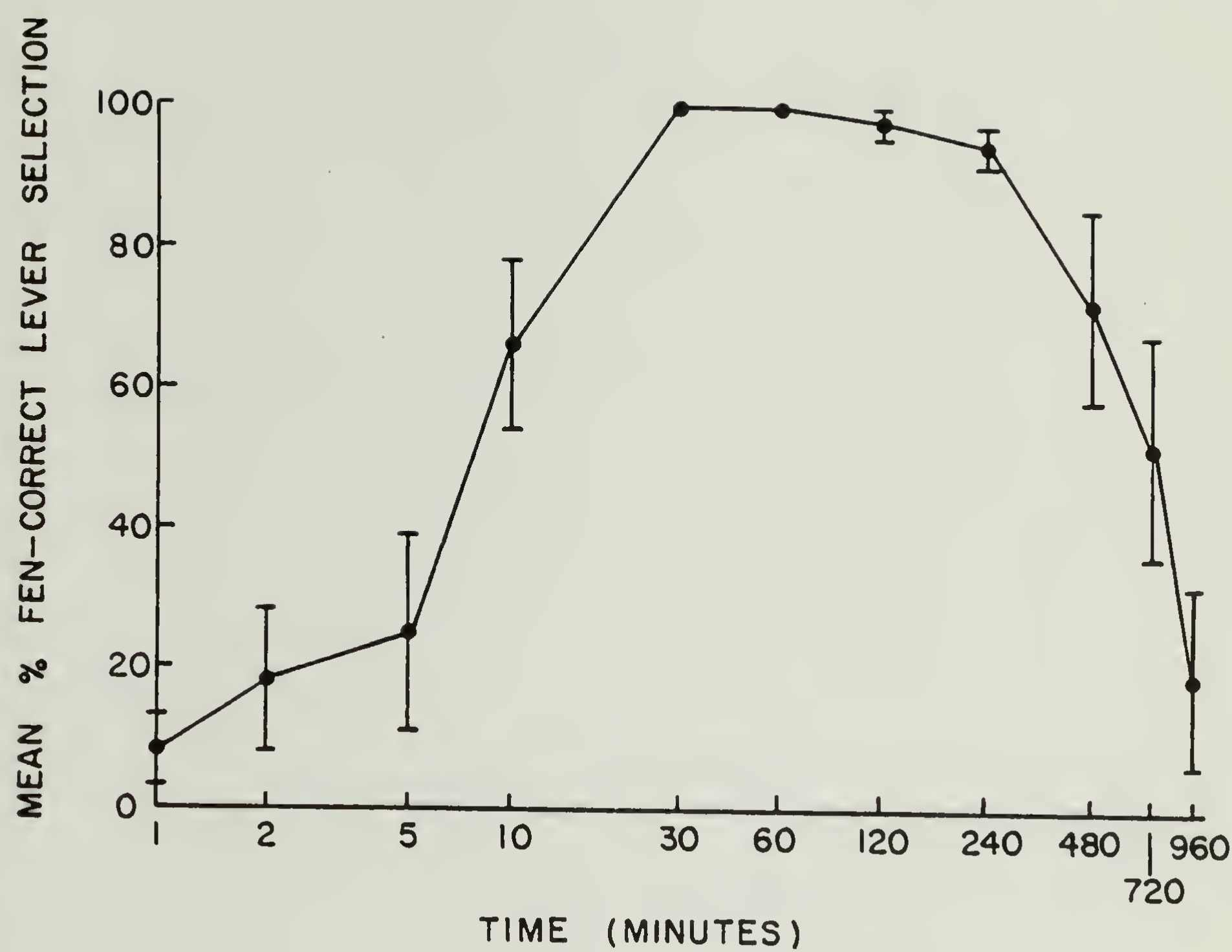

Fig. 2. Percent of total responding on the fenfluramine lever as a function of $\mathrm{minutes}$ since injection. Rats were returned to their home cages after injections for the allotted time before testing was carried out. Each point represents the mean \pm 1 SEM for 10 rats. 
cue has a rather lengthy duration, the drug still $50 \%$ effective after 12 hours. It should be noted that between 30 and 120 minutes following drug injection, fenfluramine correct responding was virtually perfect, in all animals. Based on this data, all future tests using fenfluramine were carried out 60 minutes following drug administration.

Experiment 2, The dose response relationship.

Having clearly established the temporal parameters of the fenfluramine cue, I next generated a dose response curve for fenfluramine. Rats trained to discriminate $3 \mathrm{mg} / \mathrm{kg}$ fenfluramine from saline were tested 60 minutes following injection of various doses of drug.

From the data in Fig. 3, it can be seen that by varying the dose of fenfluramine, a stimulus generalization curve is produced. The percentage of responding on the fenfluramine lever decreased monotonically as the dose of drug decreased.

It should be noted that a dose of $2 \mathrm{mg} / \mathrm{kg}$ fenfluramine elicits $97 \%$ drug-correct responding. This "threshold dose", defined as the lowest dose of drug capable of evoking reliable fenfluramine-correct responding, would appear to be the appropriate dose to manipulate in studies of fenfluramine antagonists. Attempting to antagonize a larger dose of fenfluramine, would most likely require proportionately larger doses of antagonists. The key in these antagonistic experiments is to block the cue before reaching the point of drug-induced behavioral suppression (i.e., toxic or non-specific effects). 


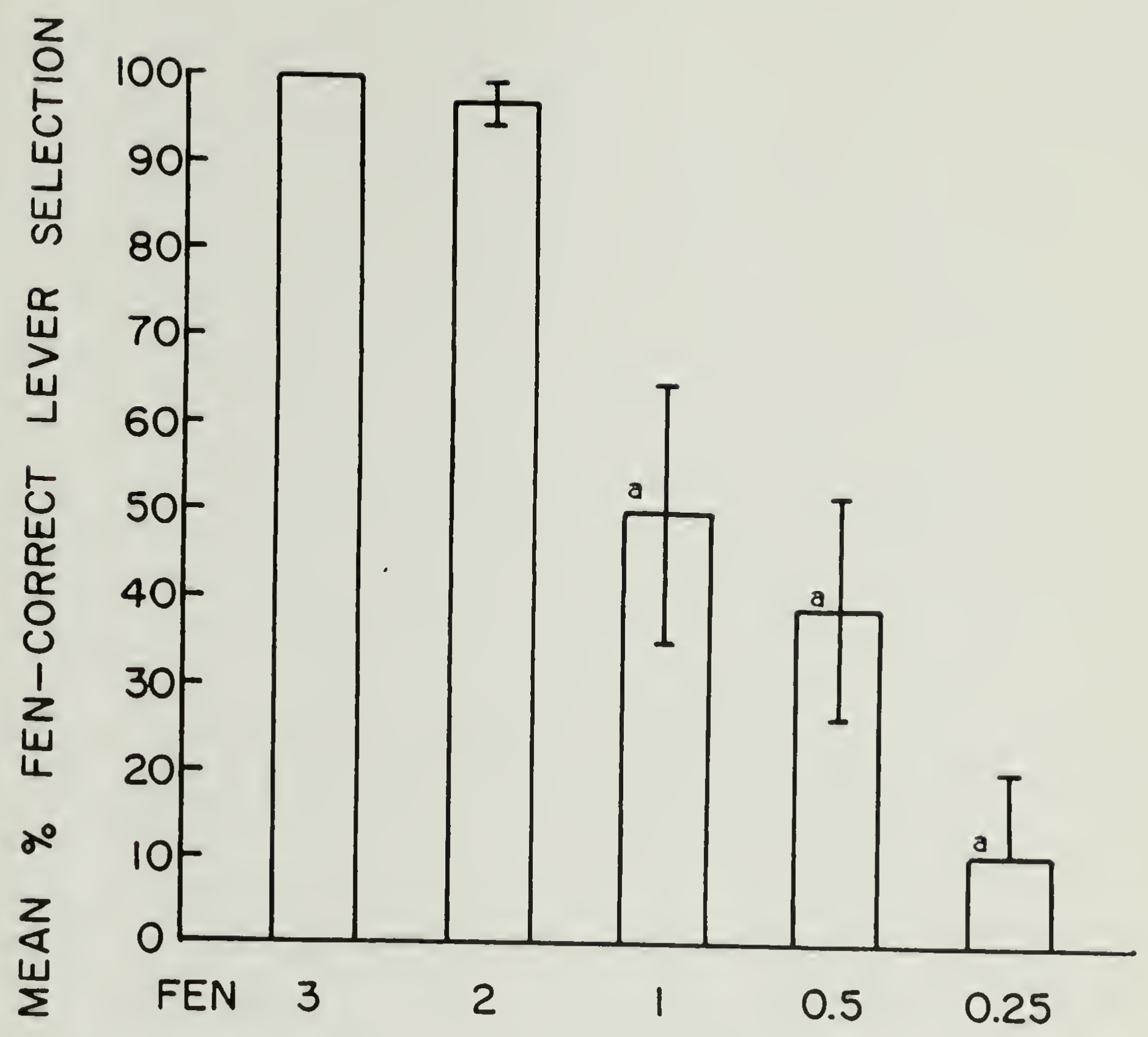

Fig. 3. Percent responding on the fenfluramine lever as a function of dose. All injections were given 1 hour prior to testing and each value represents the mean \pm 1 SEM for 10 rats. "a" denotes values that differ significantly (one-talled; $p: 0.05$; Student's t-test) from the fenfluramine $2 \mathrm{mg} / \mathrm{kg}$ value. 
For this reason, in all subsequent antagonistic studies, fenfluramine $2 \mathrm{mg} / \mathrm{kg}$ was the dose administered.

In order to monitor any changes in fenfluramine sensitivity during the length of this experiment, 3 or 4 animals, randomly selected on each test day from the group of available subjects, received a $2 \mathrm{mg} / \mathrm{kg}$ dose of fenfluramine. Fenfluramine-correct responding in these animals was virtually perfect throughout the course of this study, with the median and mean daily values 100 and $97.4 \%$ respectively. This suggests that tolerance, as might be demonstrated by a change in drug discrimination sensitivity, did not occur with chronic administration of fenfluramine.

\section{Experiment 3 , Isomeric specificity of the fenfluramine cue.}

In an attempt to explain the mechanism by which fenfluramine reduces central stores of brain 5-HT, an effect considered important in its behavioral effects, Buczko et al. (1975) demonstrated that fenfluramine inhibits the uptake of $5-\mathrm{HT}$ and induces its release by rat blood platelets. Both effects were concentration dependent and in both cases the $(+)$-isomer was more active than the (-) form. If this neurochemical action of fenfluramine on the 5-HT system underlies the behavioral effects of fenfluramine, then one might expect the discriminative stimulus properties of fenfluramine to exhibit a similar stereospecificity.

To this end, we investigated the stimulus generalization properties of the (+)-and (-)-isomeric forms of fenfluramine, 101.6 
and $99.2 \%$ pure respectively (UV analysis in ethanol solution by Robins Research Laboratories).

Although at each of the 4 doses tested (see Fig. 4), the $(+)$-isomer was more potent than the $(-)$-isomer at eliciting fenfluramine-correct responding, this difference was only significant with the $2 \mathrm{mg} / \mathrm{kg}$ doses. Responding similar to the $2 \mathrm{mg} / \mathrm{kg}$ dose of the raceme was produced by $2 \mathrm{mg} / \mathrm{kg}$ of the $(+)$ form or $3 \mathrm{mg} / \mathrm{kg}$ of the (-) form. Surprisingly, at no dose tested, was the (t)isomer significantly different from the racemic mixture at eliciting fenfluramine-correct responding.

Our demonstration that the $(+)$-isomer of fenfluramine is more effective than the (-)-isomer at inducing drug-correct responding parallels the in vitro results of Buczko et al. (1975), supporting the hypothesis that the 5-HT system might be involved in the discriminative stimulus properties of fenfluramine.

Experiment 4, Generalization of the fenfluramine cue.

The purpose of this phase of our experiment was to investigate the pharmacological specificity of the fenfluramine cue. More specifically, our attempt was to determine whether or not the qualitative aspects of the drug-produced interoceptive cue fall within a specific pharamcological class. Therefore, various compounds known to either enhance or diminish the effects of serotonin were tested for their ability to generalize to the discriminative cue produced from $3 \mathrm{mg} / \mathrm{kg}$ fenfluramine.

From the results presented in Table 1 , it can be seen that of 


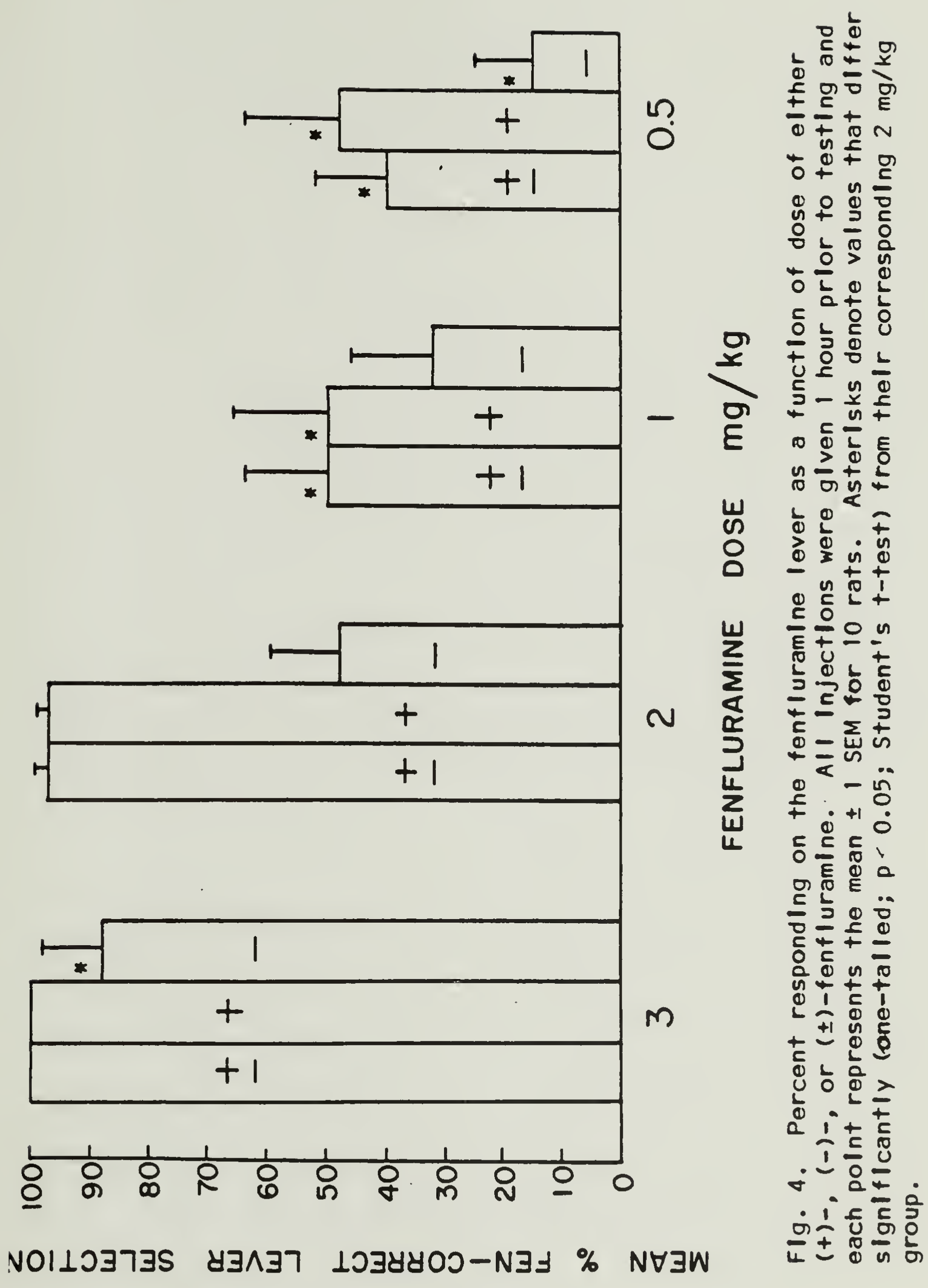


TABLE

OISCRIMIMATIVE PROPERTIES OF FENFLURMINE NO RELATEO COMPOUNOS

\begin{tabular}{|c|c|c|c|c|c|c|}
\hline Compound $(\bullet)$ & $\begin{array}{l}\text { Dose } \\
(n g / k g)\end{array}$ & n & $\begin{array}{l}\text { Ifor } \\
\text { love }\end{array}$ & & $\begin{array}{l}\text { I urani } \\
\text { solect }\end{array}$ & Ine 9 \\
\hline Fentluraine $(60)$ & 30 & $24 / 24$ & 97.4 & \pm & 1.9 & b \\
\hline Salime $(60)$ & $2.0^{2}$ & $24 / 24$ & 1.1 & \pm & 1.3 & - \\
\hline Mothysergide $(30)$ & $\begin{array}{l}2.5 \\
5.0 \\
10 \\
20 \\
40\end{array}$ & $\begin{array}{r}10 / 10 \\
10 / 10 \\
9 / 10 \\
10 / 10 \\
8 / 11\end{array}$ & $\begin{array}{l}2.6 \\
0.9 \\
9.2 \\
3.9 \\
5.1\end{array}$ & $\begin{array}{l} \pm \\
\pm \\
\pm \\
\pm\end{array}$ & $\begin{array}{l}1.9 \\
1.0 \\
8.3 \\
2.8 \\
3.5\end{array}$ & $\begin{array}{l}\bullet \\
. \\
. \\
.\end{array}$ \\
\hline Cinamearin $(30)$ & $\begin{array}{l}2.5 \\
5.0 \\
10 \\
20 \\
30\end{array}$ & $\begin{array}{c}10 / 10 \\
10 / 10 \\
10 / 10 \\
10 / 12 \\
8 / 11\end{array}$ & $\begin{array}{r}1.8 \\
0.0 \\
11.1 \\
0.9 \\
4.4\end{array}$ & $\begin{array}{l}1 \\
\pm \\
\pm \\
1\end{array}$ & $\begin{array}{l}1.3 \\
0.0 \\
9.4 \\
1.0 \\
5.1\end{array}$ & $\begin{array}{l}\bullet \\
\bullet \\
. \\
.\end{array}$ \\
\hline Finosertine $(60)$ & $\begin{array}{c}2.5 \\
5.0 \\
10\end{array}$ & $\begin{array}{l}10 / 10 \\
10 / 10 \\
8 / 10\end{array}$ & $\begin{array}{l}2.9 \\
5.1 \\
2.6\end{array}$ & $\begin{array}{l} \pm \\
\pm\end{array}$ & $\begin{array}{l}3.0 \\
3.5 \\
1.9\end{array}$ & $\begin{array}{l}\bullet \\
- \\
-\end{array}$ \\
\hline $\begin{array}{c}\text { p-chlorompremine } \\
(60)\end{array}$ & $\begin{array}{l}0.125 \\
0.25 \\
0.5\end{array}$ & $\begin{array}{l}10 / 10 \\
10 / 10 \\
10 / 10\end{array}$ & $\begin{array}{l}24.7 \\
39.1 \\
90.3\end{array}$ & $\begin{array}{l} \pm \\
\pm\end{array}$ & $\begin{array}{r}13.6 \\
16.8 \\
7.5\end{array}$ & $\begin{array}{ll}a & b \\
0 & b \\
b\end{array}$ \\
\hline $\begin{array}{l}p \text {-ti woromphotanins } \\
(60)\end{array}$ & $\begin{array}{l}1.0 \\
2.0 \\
3.0 \\
4.0\end{array}$ & $\begin{array}{r}10 / 10 \\
10 / 10 \\
9 / 13 \\
3 / 10\end{array}$ & $\begin{array}{r}3.6 \\
46.8 \\
44.0 \\
100\end{array}$ & $\begin{array}{l} \pm \\
\pm \\
\pm\end{array}$ & $\begin{array}{r}5.9 \\
16.0 \\
14.6 \\
0.0\end{array}$ & $\begin{array}{ll}0 & \\
0 & 0 \\
0 & 0 \\
0\end{array}$ \\
\hline
\end{tabular}

- injection tin prior to testing in minutes.

np Nuwoer of onimels showing sufficlent responding (10 responses on elther lever) within 10 minute extinction test.

n. Nunber of onimals tested.

q Eech value represents the moan 1 I SEM of the number of onlmals showing sufficient responding at that dose.

$2 \mathrm{ml} / \mathrm{kg}$.

- Significantly differont from the fenfluramino $3 \mathrm{mg} / \mathrm{kg}$ velue ( 1-tolled: $p<0.05$; Student's t-test).

b Significantiy different from the sallne value ( 1-tolled; $p<0.05$ : Student's t-test). 
all the compounds tested, only p-chloroamphetamine (PCA) and pfluoroamphetamine (PFA), two halogenated amphetamine derivatives structurally related to fenfluramine, demonstrated any stimulus generalization to the fenfluramine cue. It should be noted that fluoxetine, methysergide and cinanserin, at all doses tested, including doses inducing behavioral suppression, did not elicit fenfluramine-correct responding, suggesting that the animals were not merely responding along a "drugged-not-drugged" continuum, but to something more specific.

Upon closer examination (see Fig. 5), one can see that the stimulus generalization gradients resulting from the administration of PCA and PFA are monotonic and dose dependent. Only one-sixth of the fenfluramine training dose is required for PCA to produce significant generalization to the fenfluramine stimulus, whereas a $4 \mathrm{mg} / \mathrm{kg}$ dose of PFA, slightly larger than the training dose of fenfluramine, was required for reliable generalization. However, it should be noted that only 3 of 10 animals tested with $4 \mathrm{mg} / \mathrm{kg}$ PFA responded sufficiently, with the remainder not pressing either lever the requisite 10 times within the 10 minute test period. These results illustrate the high degree of chemical and pharmacological similarity necessary for generalization to occur using this behavioral procedure, but when equally effective doses are used, drugs with similar pharmacological actions are relatively indistinguishable from each other. 

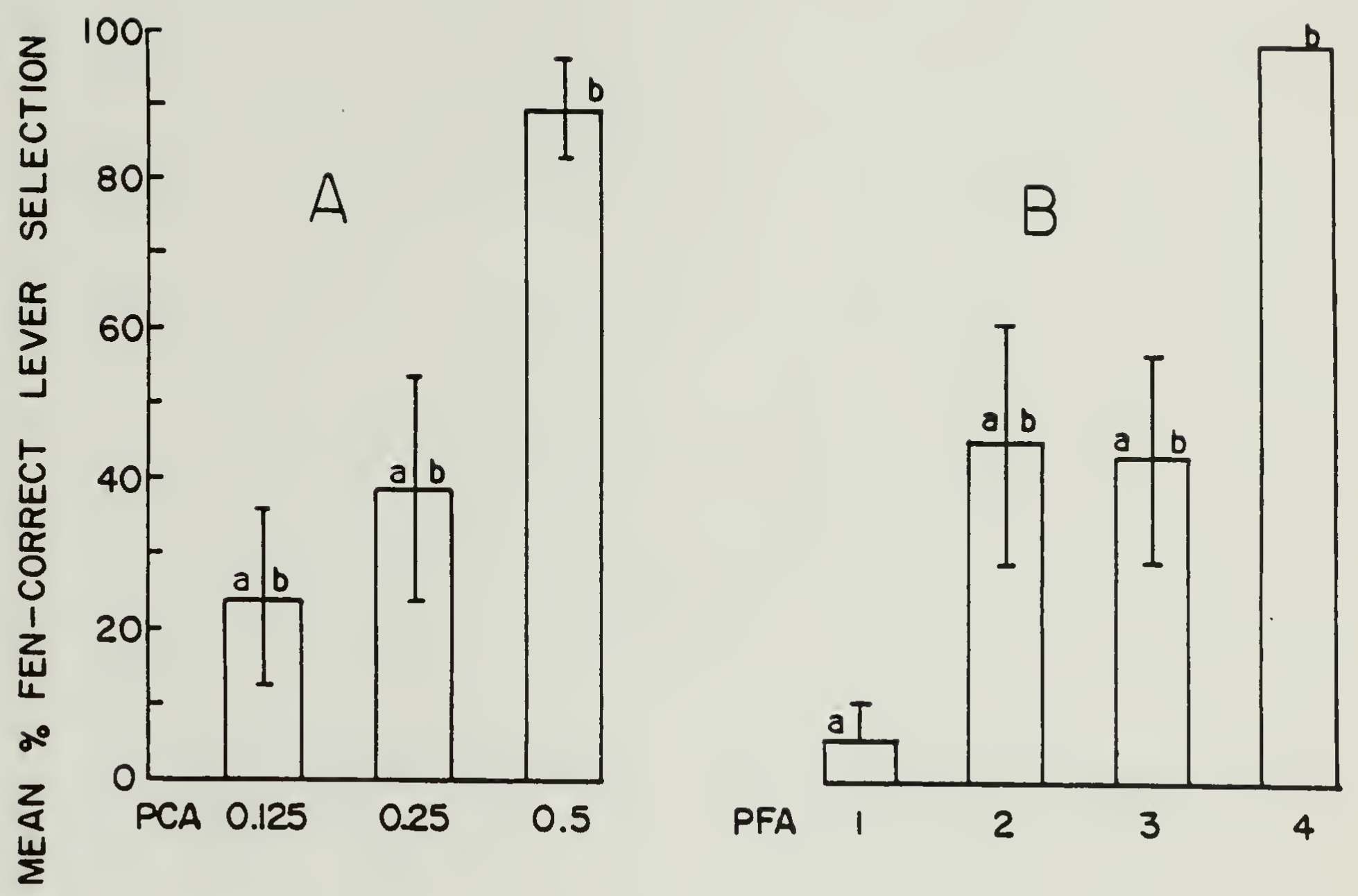

Fig. 5. Percent responding on the fenfluramine lever as a function of dose of elther $p$-chloroamphetamine (PCA) or $p$-fluoroamphetamine (PFA). All Injectlons were given 1 hour prlor to testing and in the absence of fenfluramine. Each polnt represents the mean \pm 1 SEM for the number of rats responding sufflclently at each dose (see Table 1).. "a" and "b" denote values that differ significantly (onetalled; $p<0.05$; Student's t-test) from the $3 \mathrm{mg} / \mathrm{kg}$ fenfluramine and sallne groups respectively. 
Experiment 5, Antagonism of the fenfluramine cue.

In order to identify, somewhat more specifically, the pharmacological action upon which the discriminative stimulus property of fenfluramine is based, an attempt was made to antagonize the fenfluramine cue with two types of agents; 5-HT receptor blockers and a 5-HT reuptake inhibitor. Both the inhibition of 5-HT reuptake and the inducement of its release increase the synaptic concentration of 5-HT. If the resulting enhanced stimulation of 5-HT post-synaptic receptors is instrumental in producing the discriminative cue, then a 5-HT receptor blocker might be expected to antagonize or block the cue. We therefore evaluated the effects of two putative 5-HT receptor blockers, methysergide and cinanserin, on the discriminative property of fenfluramine.

From the results illustrated in Figures 6 and 7 , it can be seen that both methysergide and cinanserin, administered 30 minutes following injection of fenfluramine and 30 minutes prior to testing, antagonized the fenfluramine cue. The antagonism was dose dependent and the values were significantly different from the $2 \mathrm{mg} / \mathrm{kg}$ fenfluramine only group for all but the lowest dose of each receptor blocker tested. At no dose tested did the animals respond as if injected with saline, indicating that the cue was not completely blocked, merely significantly antagonized. This suggests that the availability of 5-HT receptors to released transmitter substance is probably an integral component, but not solely responsible for elicitation of fenfluramine's discriminative cue. 


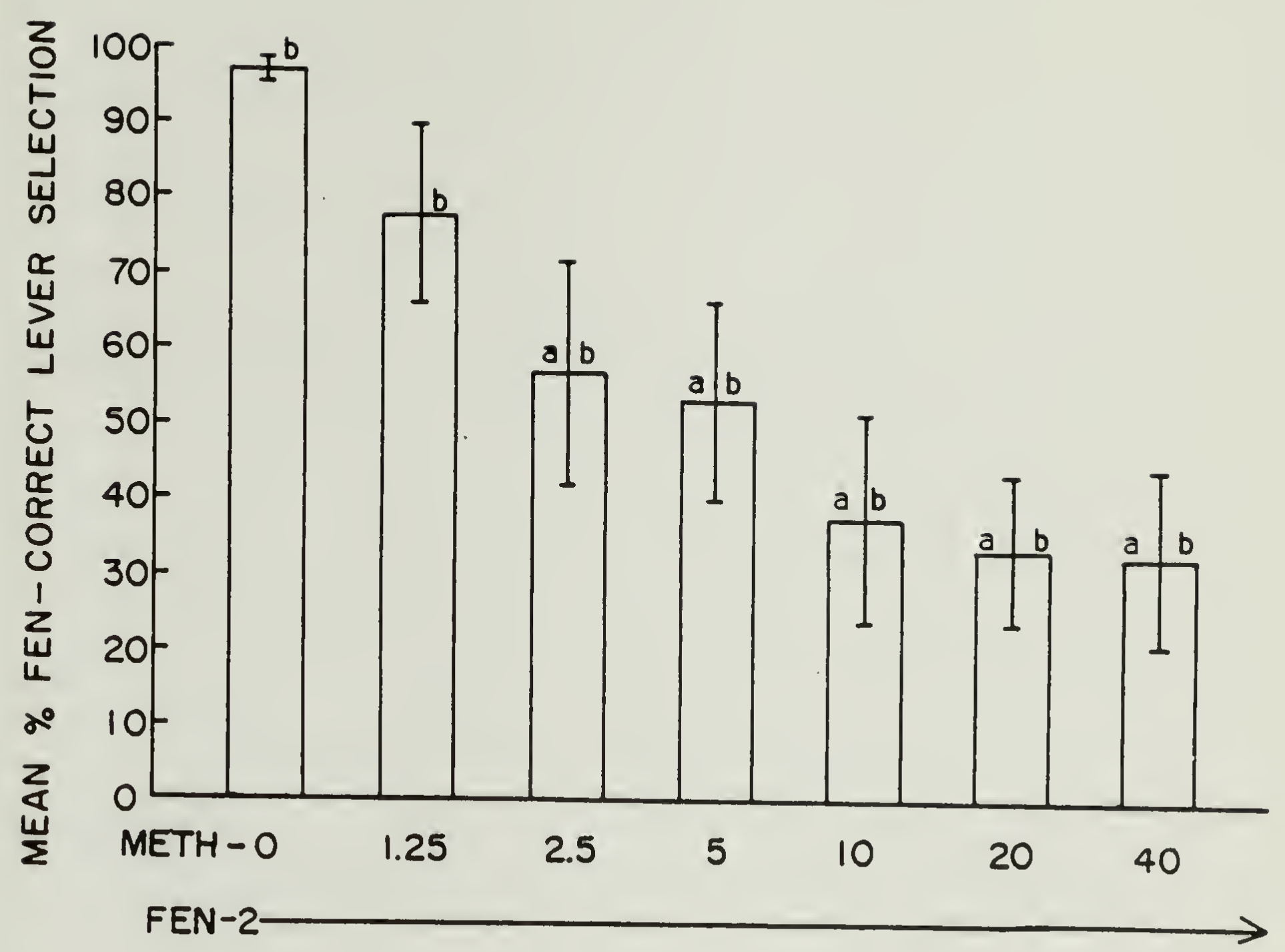

FIg. 6. Percent responding on the fenfluramine lever as a function of dose of methysergide (METH), administered 30 minutes fol lowing injection of $2 \mathrm{mg} / \mathrm{kg}$ fenfluramine and 30 minutes prlor to testing. Each point represents the mean \pm 1 SEM for 10 rats. "a" and "b" denote values that differ slgniflcantly (one-talled; $p<0.05$; Student's t-test) from the $2 \mathrm{mg} / \mathrm{kg}$ fenfluramine and sallne groups respectively. 


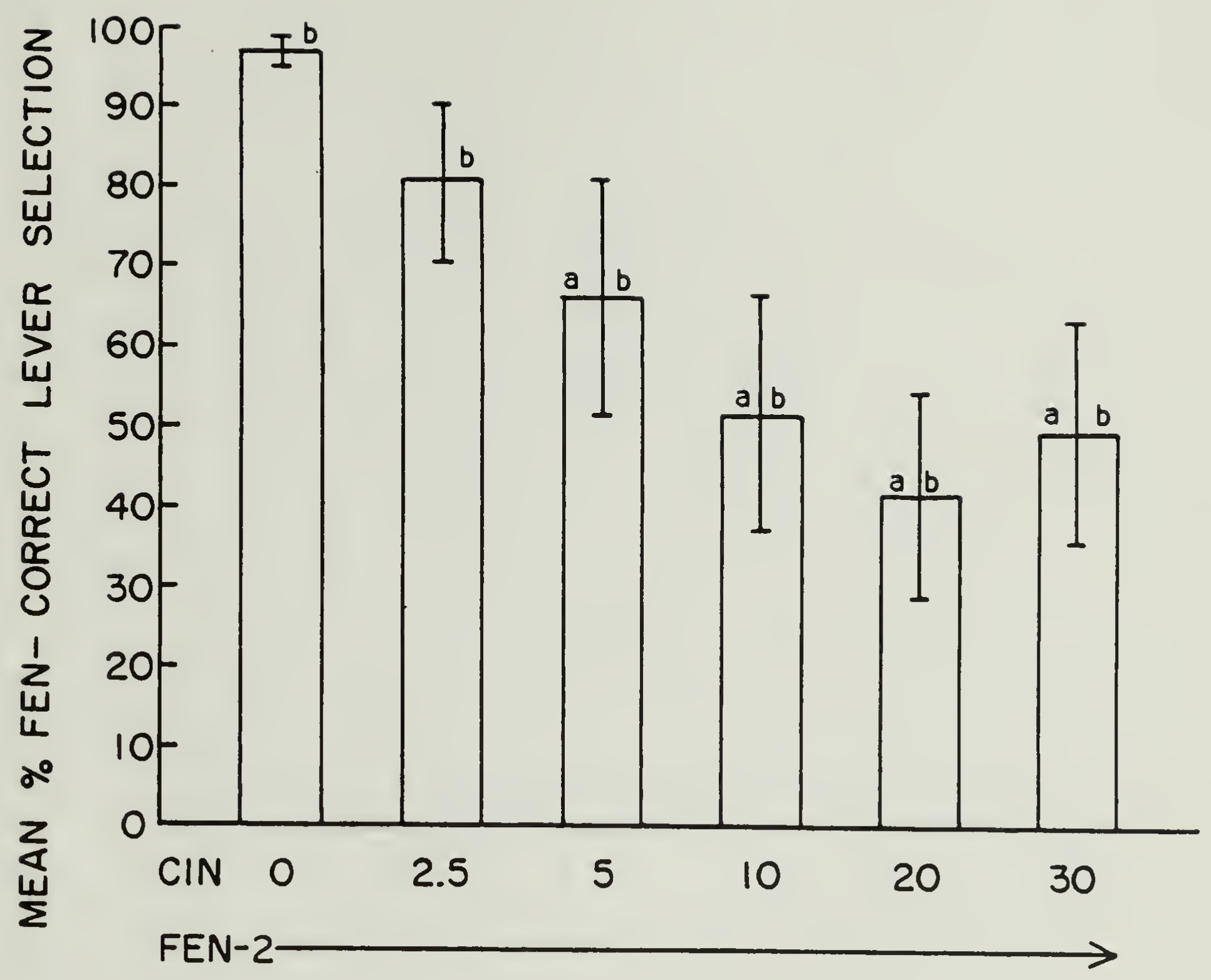

Fig. 7. Percent responding on the fenfluramine lever as a function of dose of cinanserin (CIN), administered 30 minutes following Injection of $2 \mathrm{mg} / \mathrm{kg}$ fenfluramine and 30 minutes prlor to testing. Each polnt represents the mean \pm 1 SEM for 10 rats. "a" and " $b$ " denote values that differ slgniflcantly (one-talled; $p=0.05$; Student's t-test) from the $2 \mathrm{mg} / \mathrm{kg}$ fenfluramine and salline groups respectively. 


\section{Experiment 6, Fluoxetine-fenfluramine interactions.}

The precise mechanism of action of the 5-HT depletion resulting from the administration of halogenated amphetamine derivatives such as fenfluramine, PCA, or PFA is still not clear (presumably by inducement of 5-HT release from nerve terminals), yet access of these drugs to the 5-HT uptake pump for several hours appears necessary. Fuller et al. (1974) reported that the preinjection of FXT or chlorimipramine (CMI), selective and potent inhibitors of the 5-HT uptake pump, blocked the 5-HT depletion induced by PCA. Not only was preinjection effective, but postinjection of CMI (Meek et al., 1971) or FXT (Fuller et al., 1975) also effectively reversed the depletion. In a similar experiment carried out in fenfluramine treated animals, Clineschmidt et al. (1978) demonstrated that FXT can prevent (via preinjection) or reverse (via postinjection) the 5-HT depletion characteristic of fenfluramine.

In this experiment, an attempt was made to investigate the requisite access of fenfluramine to the 5-HT uptake mechanism for elicitation of the fenfluramine cue. Therefore FXT was administered either 1 hour prior to, concurrently with, or 30 minutes following a $2 \mathrm{mg} / \mathrm{kg}$ injection of fenfluramine.

In Fig. 8A it can be seen that FXT, when administered 1 hour prior to fenfluramine, antagonized the discriminative cue. However the dose relationship was inverse, with only the lower doses significantly effective. When FXT was given concurrently with (see 


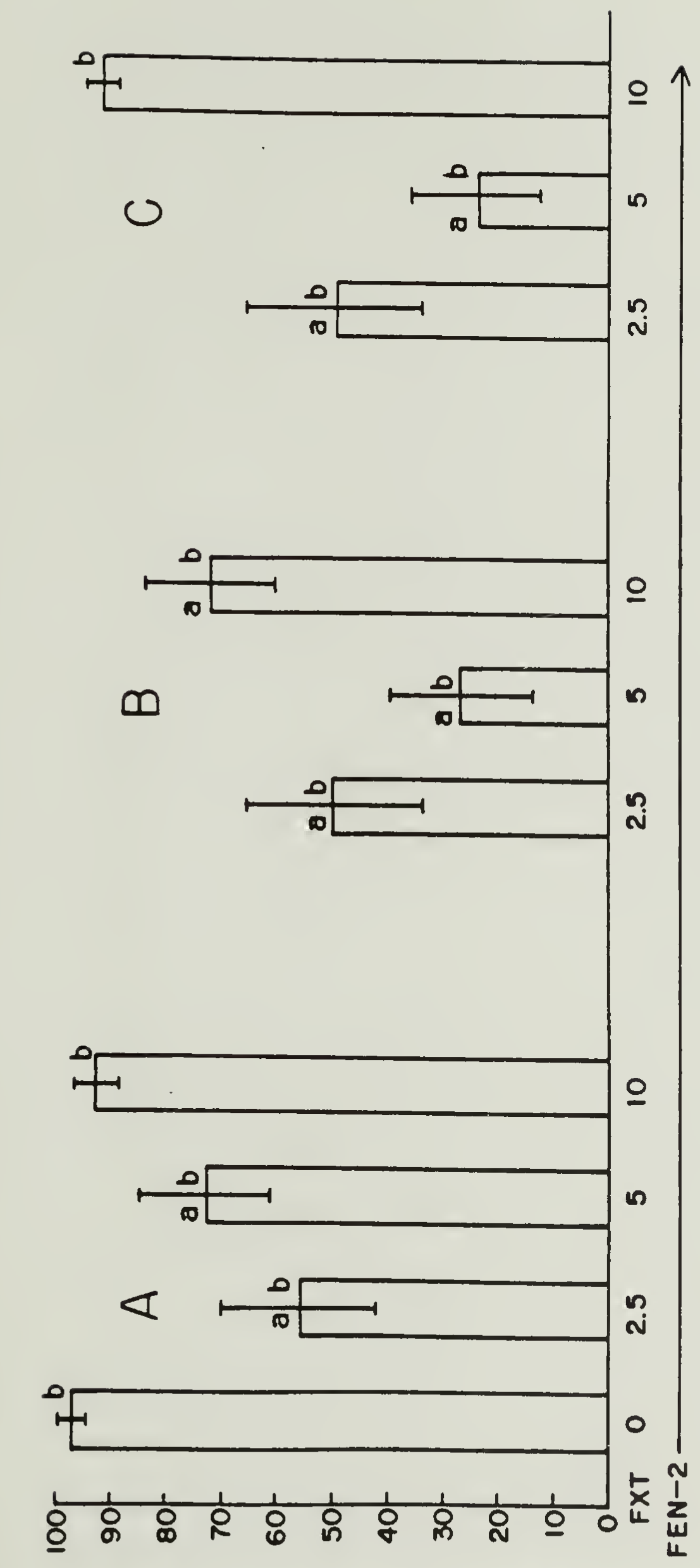

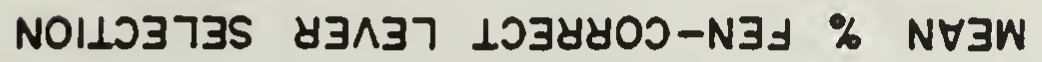

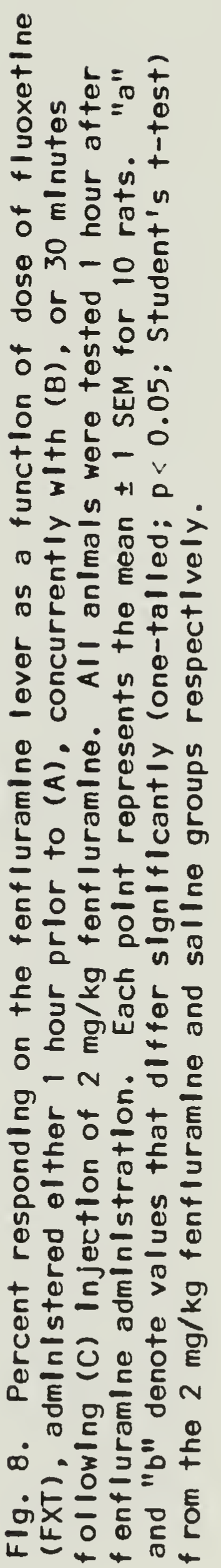


Fig. 8B) or 30 minutes following fenfluramine (see Fig. 8C), the dose relationship is less clear. In both cases the $5 \mathrm{mg} / \mathrm{kg}$ dose was the most potent at counteracting fenfluramine-correct responding, but not significantly different from the $2.5 \mathrm{mg} / \mathrm{kg}$ dose.

Based on the ability of FXT to inhibit the uptake of fenfluramine into the presynaptic terminal, one might expect the $10 \mathrm{mg} / \mathrm{kg}$ dose of FXT to be more potent than the $5 \mathrm{mg} / \mathrm{kg}$ dose at cue antagonism. From Fig. 8 it can be seen that the $10 \mathrm{mg} / \mathrm{kg}$ dose of FXT, at all 3 times administered, is the least effective at blocking the discriminative cue, with only the concurrent administration of $10 \mathrm{mg} / \mathrm{kg} \mathrm{FXT}$ demonstrating any significant antagonistic properties.

This apparent contradiction can perhaps be explained if one considers the effect of FXT on the 5-HT system, irrespective of its influence on fenfluramine. FXT, a blocker of 5-HT reuptake, increases synaptic levels of transmitter substance, an agonistic property that may only be evidenced with high doses of the reuptake inhibitor. For example, a low dose of FXT, capable of blocking FEN uptake and thus the fenfluramine-induced release of 5-HT, may itself not be sufficient to enhance post-synaptic 5-HT activity via 5-HT uptake inhibition. The result of the decreased release of 5-HT would be an insufficient stimulation of $5-\mathrm{HT}$ post-synaptic receptors, leading to saline lever selection. On the other hand, a larger dose of FXT, clearly sufficient to block the fenfluramine-induced release of 5-HT, may itself significantly increase synaptic levels of $5-\mathrm{HT}$ via a more pronounced inhibition of transmitter substance reuptake. The net effect in this case 
would be enhanced stimulation of 5-HT post-synaptic receptors and eilcitation of the discriminative cue, leading to fenfluraminecorrect responding.

From this study it can be seen that FXT, a selective and potent inhibitor of the 5-HT uptake mechanism, can antagonize the discriminative stimulus properties of fenfluramine. It would appear that the continued uptake of fenfluramine into the presynaptic nerve terminal for a critical period of time is necessary for elicitation of the discriminative cue. It may be that a substantial intraneuronal accumulation of fenfluramine needs to be achieved to provide the discriminative cue and FXT is able to interrupt this process. With high doses of FXT, the situation is further complicated as FXT may have a direct effect on the 5-HT system that counteracts the influence of FXT on fenfluramine.

Experiment 7 , Is satiety the fenfluramine cue?

Fenfluramine is clinically prescribed as an anorectic agent since it reduces food intake, weight gain, and the subjective feeling of hunger (Pinder et al., 1975). In our final experiment, we attempted to evaluate the possible role of feelings of satiety as the basis of fenfluramine's discriminative cue. Therefore, animals were food deprived either 0,24 , or 48 hours and tested following both saline and fenfluramine administration. During a 10 minute test period the following measures were recorded: the latency of the first response, the number of incorrect responses before the first reinforcement, and the total 
number of responses during the 10 minute session.

The results were that all animals, when injected with either saline or fenfluramine, regardless of their state of hunger, selected their appropriate levers at almost $100 \%$ accuracy. If the animal's state of hunger was the discriminative cue, then one might have expected the animals injected with saline and food deprived for 0 hours (satiated), to respond as if they had received an injection of fenfluramine. Conversely, 48 hour food-deprived, fenfluramine-injected animals might have been expected to respond as if they had been administered saline. Clearly this did not occur. Cue detection, as evidenced by saline- or fenfluramine-correct lever selection, was entirely independent of the state of hunger.

Moreover, as shown in Fig. 9A, the rate of food-reinforced operant responding during the 10 minute session, under both treatment conditions, did vary as a function of the length of food deprivation. An analysis of variance for the overall food deprivation effect was statistically significant $(F=20.39 ; \mathrm{df}=2,18 ; \mathrm{p}<0.001)$. Although the response rate following saline administration was consistently higher than that after injection of fenfluramine, the difference was not significant $(F=2.92 ;$ df $=1,9 ; 0.1<p<0.2)$.

It can also be seen in Fig. 9B that under both treatment conditions, the latency of the animal's initial response decreased as the state of hunger was increased. An analysis of variance revealed that this overall food deprivation effect was significant $(F=1307 ; \mathrm{df}=2,18 ; \mathrm{p}<0.001)$. Regardless of the state of hunger, 

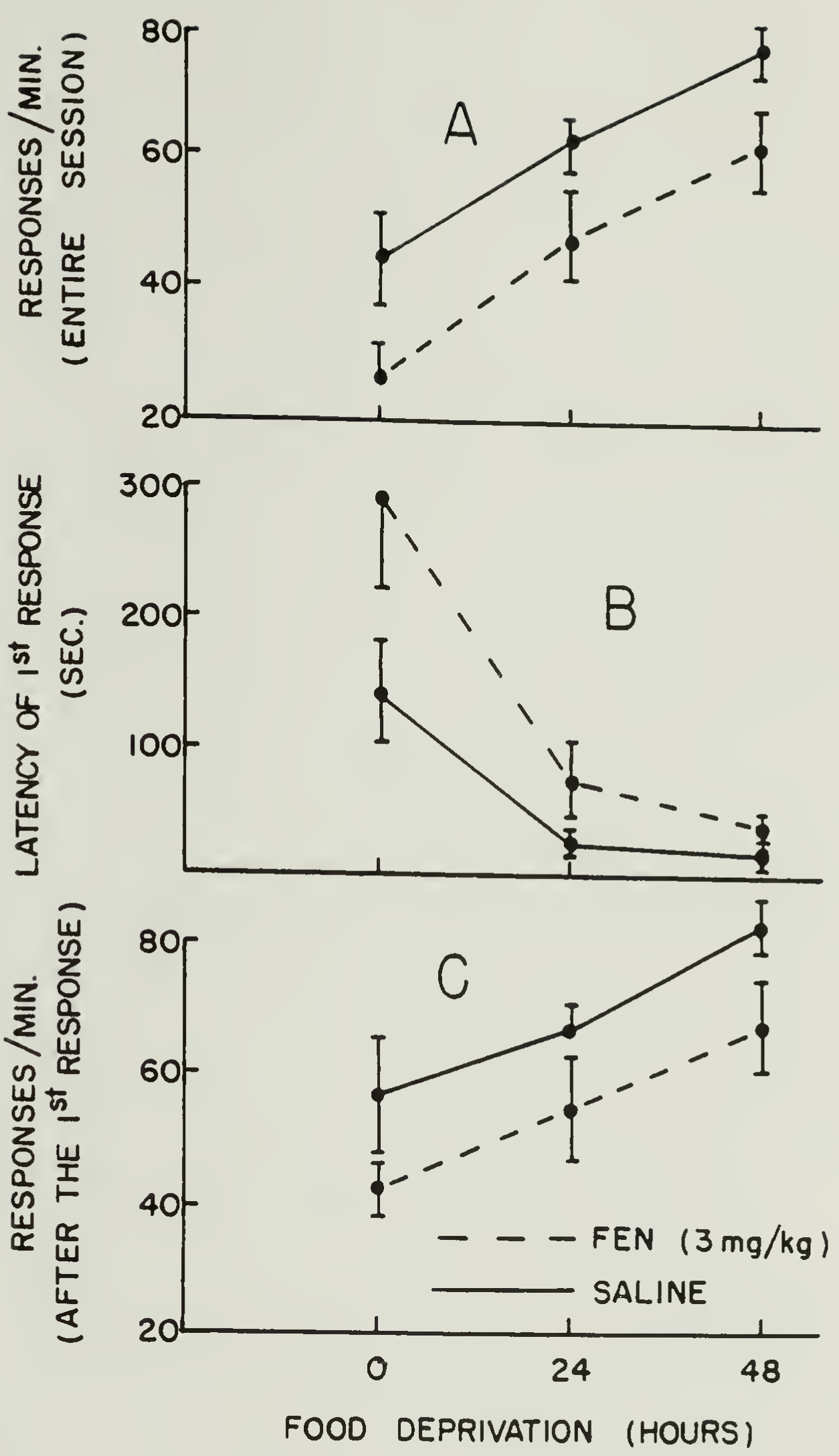

Fig. 9. Rate of responding ( $A$ and $C$ ) and latency of first response ( $B$ ), as a function of length of food deprivation. All animals were tested I hour following injection of sallne or $3 \mathrm{mg} / \mathrm{kg}$ fenfluramine. Each polnt represents the mean \pm I SEM for the same 10 rats. 
the latencies were consistently lower following saline administration than after administration of fenfluramine. This overall difference was highly significant $(F=104 ; \mathrm{df}=1,9 ; \mathrm{p}<0.001)$.

Because first. response latencies varied as a function of both the drug treatment and the length of food deprivation, the actual time that each animal spent lever pressing was not 10 minutes. Therefore, Fig. $9 \mathrm{~A}$ does not accurately represent the rate of responding. To compendate for the effect of the drug and deprivation treatments on latencies, response rates were recalculated for only the time interval subsequent to each animal's initial response. This data is shorn in Fig. 9C. It can be seen that following this adjustment, the overall drug treatment effect was now significant $(F=11.28 ; \mathrm{df}=1,9 ; p<0.001)$. An analysis of variance for the overall food deprivation effect continued to be highly significant $(F=20.07 ; \mathrm{df}=2,18 ; \mathrm{p}<0.001)$. This indicates that the observed differences in overall rate of responding illustrated in Fig. 9A are not solely a result of the drug and deprivation effects on first response lätencies.

These results demonstrate that although both the latency and rate of operant responding vary as a function of the state of food deprivation, lever selection occured independently of the state of hunger. Under all conditions, each animal reliably selected the appropriate lever. Therefore, our data do not support the hypothesis that the feeling of satiety induced by fenfluramine is a factor in the drugs ability to produce an interocentive discriminative cue. 


\section{GENERAL DISCUSSION}

The control data obtained with the drug discrimination procedure indicate that fenfluramine $(3 \mathrm{mg} / \mathrm{kg}$ ) may control differential operant responding in rats on the basis of its discriminative stimulus properties. In this respect, the results are consistent with an earlier study (Goudie, 1977) using fenfluramine at the same dose. It is further shown that cue detection is optimal 30 and 120 minutes following administration of $3 \mathrm{mg} / \mathrm{kg}$ fenfluramine and is entirely independent of its effects on appetite. It had also been demonstrated that the lowest dose of drug capable of eliciting reliable discrimination is $2 \mathrm{mg} / \mathrm{kg}$.

The generalization experiment with the isomeric forms of fenfluramine indicate that the $(+)$-isomer is more potent than the (-)form at eliciting fenfluramine-correct responding. This result parallels the findings of Buczko et al. (1975), who demonstrated that the $(+)$-form of fenfluramine was the more active at initiating the release of $5-\mathrm{HT}$ and inhibiting its reuptake by rat blood platelets. Our results support the hypothesis that the 5-HT system is involved in the discriminative stimulus properties of fenfluramine.

The generalization experiments with the serotonergic drugs provide evidence that of all the compounds tested, only the two halogenated amphetamine derivatives, structurally and pharmacologically similar to fenfluramine, produce a discriminative stimulus which is 
generalized with the standard fenfluramine treatment in a dosedependent manner. This suggests that the discriminative stimulus property of fenfluramine is pharmacologically specific.

The finding that drugs which block the binding sites for endogenous serotonin also antagonize the fenfluramine cue, supports the hypothesis that the discriminative stimulus property is based upon fenfluramine's ability to enhance 5-HT transmission. This suggests that the inhibition of 5-HT reuptake and the inducement of its release by fenfluramine is not sufficient for elicitation of the drug cue, but access of the released 5-HT to 5-HT receptors appears necessary for discrimination to occur.

To further examine the involvement of the serotonergic system in the discriminative property of fenfluramine, a selective and potent inhibitor of 5-HT reuptake was tested for its effect on the fenfluramine cue. Fluoxetine (FXT), administered either prior to, concurrently with of following injection of fenfluramine, successfully antagonized the discriminative cue, indicating that the continued access of fenfluramine to the 5-HT reuptake mechanism is requisite for elicitation of the fenfluramine cue. This finding is consistent with previous reports demonstrating the ability of reuptake inhibitors to antagonize the 5-HT depleting and anorectic effects of fenfluramine. This again suggests that the behavioral effects of fenfluramine might be closely related to the drugs ability to affect the serotonergic system.

It is important to note that the studies reported here in no way allude to the locus of 5-HT action for the discriminative cue. Drug 
discrimination has been established on the basis of central (Colpaert et al., 1975) and peripheral (Colpaert et al., 1976) effects of drugs. It is also known that about $95 \%$ of the $5-\mathrm{HT}$ in the body resides outside the central nervous system (Kety, 1967). To establish the locus of the fenfluramine cue, one must either administer the drugs intraventricularly or use agents which selectively penetrate the blood brain barrier.

In conclusion, the results reported here confirm the ability of fenfluramine to produce a discriminative stimulus, enabling animals to respond differentially to the drug and no-drug conditions. It has further been demonstrated that the serotonergic system is intrinsically involved in the discriminative stimulus properties of fenfluramine. Finally, it is believed that the precision obtained in the test results were dependent upon the early data generated by the time course and dose response curves, that permitted the use of optimum doses and injection times before testing. 


\section{REFERENCES}

Alphin, R.S., Funderburk, W.H. \& Ward, J.W. (1964). Anorexigenic activity of N-ethyl-2-trifluoromethylphenylethylamine hydrochloride. Toxicol. Appl. Pharmacol., 6, 340.

Blunde11, J.E., Latham, C.J. \& Leshem, M.B. (1973). Biphasic action J. Pharm. Pharmaptamine inhibitor on fenfluramine-induced anorexia.

Blunde11, J.E. \& Leshem, M.B. (1975). The effect of 5-hydroxytryptophan on food intake and on the anorexic action of amphetamine and fenfluramine. J. Pharm. Pharmacol., 27, 31.

Brown, A., Feldman, R.S.\& Moore, J.W. (1968). Conditional discrimination learning based upon chlordiazepoxide. J. Comp. Physiol.

Buczko, W., De Gaetano, G. \& Garattini, S. (1975). Effect of fenfluramine on 5-hydroxytryptamine uptake and release by rat blood platelets. Br. J. Pharmac., 53, 563.

Clineschmidt, B.V., McGuffin, J.C., Pflueger, A.B. \& Totaro, J.A. (1975). Fenfluramine-induced enhancement of confinement motor activity: an indirect 5-hydroxytryptamine-like action? Neuropharmacology, 14, 301 .

Clineschmidt, B.V., Zacchei, A.G., Totaro, J.A., Pflueger, A.B., McGuffin, J.C. \& Wishousky, T.I. (1978). Fenfluramine and brain serotonin. Ann. N..$\underline{\text { Acad. Sci. }}$. 307, 22\%.

Colpaert, F.C., Lal, H., Niemegeers, C.J.E. \& Janssen, P.A.J. (1975). Investigations on drug produced and subjectively experienced discriminative stimuli. 1. The fentanyl cue, a tool to investigate subjectively experienced narcotic drug actions. Life Sciences,

Colpaert, F.C., Niemegeers, C.J.E.\& Janssen, P.A.J. (1976b). Theoretical and methodological considerations on drug discrimination learning. Psychopharmacology, 46, 169.

Colpaert, F.C., Leysen, J.E.M., Niemegeers, C..T.E. \& Janssen, P.A.J. (1976a). Blockade of apomorphine's discriminative stimulus properties. Relation to neuroleptic activity in neuropharmacological and biochemical assays. Pharmacol. Biochem. Behav., 5, 671.

Costa, E., Groppetti, A. \& Revuelta, A. (1971). Action of fenfluramine on momoamine stores of rat tissue. Br. J. Pharmacol., 41, 57. 
Dahlstrom, A. \& Fuxe, K. (1964). Evidence for the existence of monoamine-containing neurons in the central nervous system. Demonstration of monoamines in the cell bodies of brain stem neurons.
Acta Physiol. Scand., 62 (Supp1. 232), 1.

Duhault, J. \& Boulanger, M. (1977). Fenfluramine long-term administration and brain serotonin. Europ. J. Pharmacol., 43, 203.

Everitt, B.J.\& Hackett, N.B. (1972). Central stimulant action of fenfluramine in the rat. Brit. J. Pharmacol., 44, 342.

Fuller, R.W., Perry, K.W., Snoddy, H.D. \& Molloy, B.B. (1974) . Comparison of the specificity of 3 -(p-trifluoromethylphenoxy)-N-methyl3-phenylpropylamine and chlorimipramine as amine uptake inhibitors in mice. Europ. J. Pharmacol., 28, 233.

Fuller, R.W., Perry, K.W. \& Molloy, B.B. (1975). Effect of 3-(ptrifluoromethylphenoxy)-N-methy 1-3-phenylpropylamine on the depletion of brain serotonin by 4-chloroamphetamine. J. Pharmacol. Exp. Ther.,

Funderbruk, W.H., Hazelwood, J.C., Ruckart, R.T.\& Ward, J.W. (1971). Is 5-hydroxytryptamine involved in the mechanism of action of fenfluramine? J. Pharm. Pharmacol., 23, 468.

Fuxe, K, Farnebo, L.O., Hamberger, B. \& Ogren, S.0. (1975). On the in vivo and in vitro actions of fenfluramine and its derivatives on central monoamine neurons, especially 5-hydroxytryptamine neurons, and their relation to the anorectic activity of fenfluramine. Postgrad. Med. J., (Supp1. 1), 35.

Goudie, A.J. (1977). Discriminative stimulus properties of fenfluramine in an operant task: an analysis of its cue function. Psychopharmacology, 53, 97 .

Ho, B.T. \& Huang, J.T. (1975). Role of dopamine in d-amphetamine-induced discriminative responding. Pharmacol. Biochem. Behav., 3,1085.

Jespersen, S. \& Scheel-Kruger, J. (1970). Antagonism by methysergide of the 5-hydroxytryptamine-like action of toxic doses of fenfluramine in dogs. J. Pharm. Pharmacol., 22, 637.

Jespersen, S. \& Scheel-Kruger, J. (1973). Evidence for a difference in mechanism of action between fenfluramine- and amphetamine-induced anorexia. J.Pharm. Pharmacol., 25, 49. 
Kety, S.S. (1967). The central physiological and pharmacological effects of the biogenic amines and their correlations with behavior. The neurosciences: a study program, edited by: Quarton, G.C., MelPress, New York.

Kruk, L. (1973). Dopamine and 5-hydroxytryptamine inhibit feeding in rats. Nature New Biology, 246, 52.

Kuhn, D.M., Appel, J.B.\& Greenberg, I. (1974). An analysis of some discriminative properties of d-amphetamine. Psychopharmacology,

Lesser, M.F. \& Meyerson, $\Lambda$. (1938). Benzedrine sulfate as an aid in the treatment of obesity. N.E.J. Medicine, $218,119$.

Meek, J.L., Fuxe, K. \& Carlsson, A. (1971). Blockage of p-chlormethamphetamine-induced 5-hydroxytryptamine depletion by chlorimipramine and meperidine. Biochem. Pharmacol., 20, 707.

Opitz, K. (1967). Anorexigene Phenylalkylamine und serotoninstoffweschsel. Naunyn-Schmiedbergs Arch. Pharmak. Exp. Path.,

Overton, D.A. (1978). Discriminable effects of antihistamine drugs. Archives Internationales de Pharmacodynamie et de Therapie, $232,221$.

Pinder, R.M., Brogden, R.N., Sawyer, P.R., Speight, T.M. \& Avery, G.S. (1975). Fenfluramine: a review of its pharmacological properties and therapeutic effecacy in obesity. Drugs, 10, 245.

Rosecrans, J.4., Goodloe, M.H., Jr., Bennett, G.J. \& Hirschhorn, I.D. (1973). Morphine as a discriminative cue: effects of amine depletions and naloxone, Eur. J. Pharmaco1., 21, 252.

Samanin, R., Ghezzi, D., Valzelli, L. \& Garattini, S. (1972). The effects of selective lesioning of brain serotonin or catecholamine containing neurones on the anorectic activity of fenfluramine and amphetamine. Europ. J. Pharmaco1., 19, 318.

Schechter, M.D. \& Rosecrans, J.A. (1973). D-amphetamine as a discriminative cue: drugs with similar stimulus properties. Europ. J. Pharmacol., 21,212 .

Schechter, M.D. \& Cook, P.G. (1975). Dopaminergic mediation of the interoceptive cue produced by d-amphetamine in rats. Psychopharmacologia, 42, 185. 
Taylor, M., Goudie, A.J. \& Williams, A. (1973). The effects of chronic
fenfluramine administration pharmacologia, 31,63 . 
